\title{
Voltage Scalling Based Traffic Light Controller Design on Virtex-7 FPGA Family
}

\author{
Sujeet pandey ${ }^{1}$, Bhagwan Das $^{2}$, D M A Hussain ${ }^{3}$ \\ ${ }^{1}$ Gyancity research lab, Motihari, India \\ ${ }^{2}$ UTHM Malaysia \\ ${ }^{3}$ Aalborg University, Esberg, Denmark \\ 1elcomesujeet@gmail.com, $\underline{\text { engr.bhagwandas@ hotmail.com, }}{ }^{3}$ akh@et.aau.dk
}

\begin{abstract}
This is an apporach to design of energy efficient traffic light controller on Virtex-7 FPGA that consume low amount of power. There is a reduction of $46.31 \%, 70.11 \%$ and $82.58 \%$ in leakage power as the voltage is scale down from $1.8 \mathrm{~V}$ to $1.6 \mathrm{~V}, 1.4 \mathrm{~V}$ and $1.2 \mathrm{~V}$ respectively at ambient temperature $25^{\circ} \mathrm{C}$. There is a reduction of $52.48 \%, 75.59 \%$ and $86.96 \%$ in leakage power as the voltage is scale down from $1.8 \mathrm{~V}$ to $1.6 \mathrm{~V}, 1.4 \mathrm{~V}$ and $1.2 \mathrm{~V}$ respectively at ambient temperature $50^{\circ} \mathrm{C}$. There is a reduction of $46.31 \%, 70.11 \%$ and $82.58 \%$ in clock power as the voltage is scale down from $1.8 \mathrm{~V}$ to $1.6 \mathrm{~V}, 1.4 \mathrm{~V}$ and $1.2 \mathrm{~V}$ respectively at any value of ambient temperature.
\end{abstract}

Keyword: Verilog, FPGA, Energy Efficient design, Traffic Light Controller.

\section{INRODUCTION:}

In this work, Verilog is used as hardware description language for implementation of traffic light controller. It shows Red, Green and Yellow color at a predefined interval. Voltage scaling is used as energy efficient design. Traffic light controllers are used to control the movement of the vehicles. Power dissipation is measured on XPOWER simulator. In this paper we have to use Virtex-7 FPGA family to making energy efficient design traffic light controller. Y denotes Yellow, R denotes Red and $\mathrm{G}$ denote Green color of traffic light controller. There are two inputs and 12 outputs in design under consideration. We have generated RTL schematic, technology schematic. Top level schematic of Traffic Light Controller as shown in figure 1. It shows basic input required for traffic light controller and basic output required for our design under test. Verilog is a language which is similar to the $\mathrm{C}$ programming language, which was already widely used in engineering software development. A Verilog design consists of a hierarchy of modules. Synthesis software algorithmically transforms the Verilog source into a netlist, a logically equivalent description consisting only of elementary logic primitives (AND, OR, NOT, ip- ops, etc.) that are available in a speci c FPGA or VLSI technology. Virtex7 is $28 \mathrm{~nm}$ technology based FPGA. LVCMOS18 is the default IO standards. 


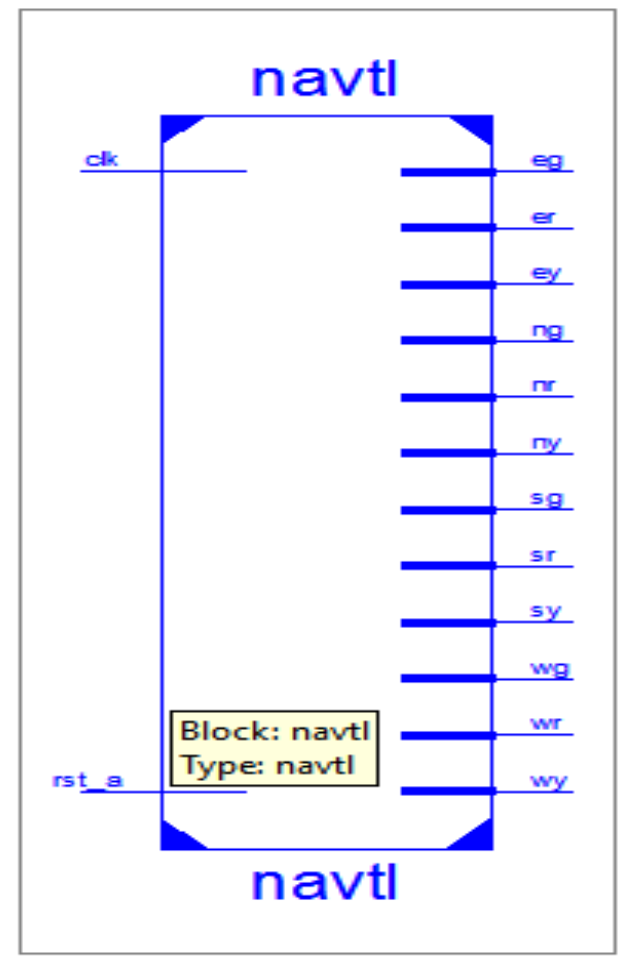

Figure 1 Top Level Schematic view of Traffic Light Controller.

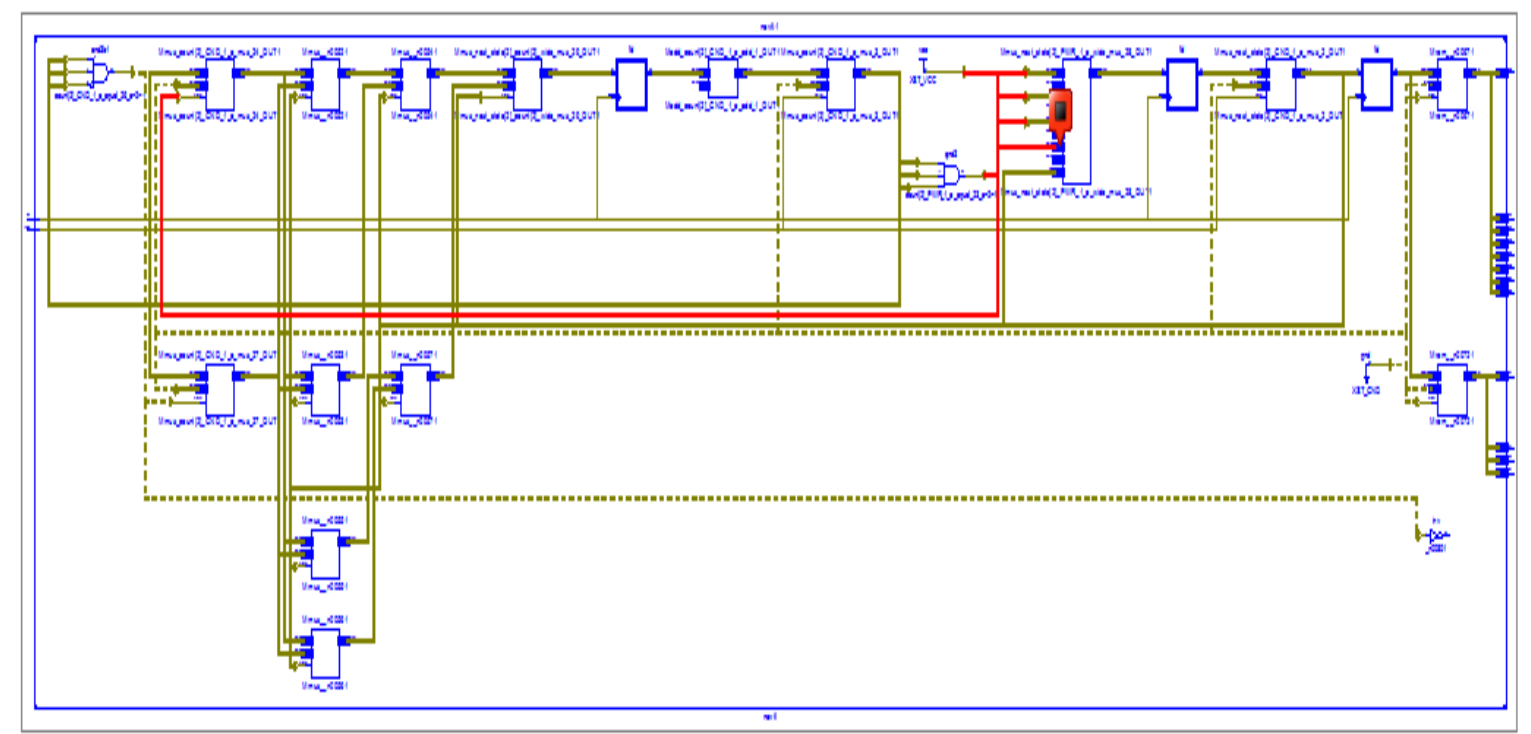

Figure 2 RTL Schematic view of Traffic Light Controller

Internal Architecture of RTL Schematic of traffic light controller is shown in Fig. 2. This architecture shows different multiplexer, gates and other basic primitive circuits used in RTL schematic. Technology schematic of our design is shown in Fig. 3.In this design we are using Number of Slice Registers, Number of Slice LUTs, Number used as logic, Number of occupied Slices, Number of slice register sites lost to control set restrictions and Number of bonded IOBs are 9,15,15,9,7 and 14 respectively. 


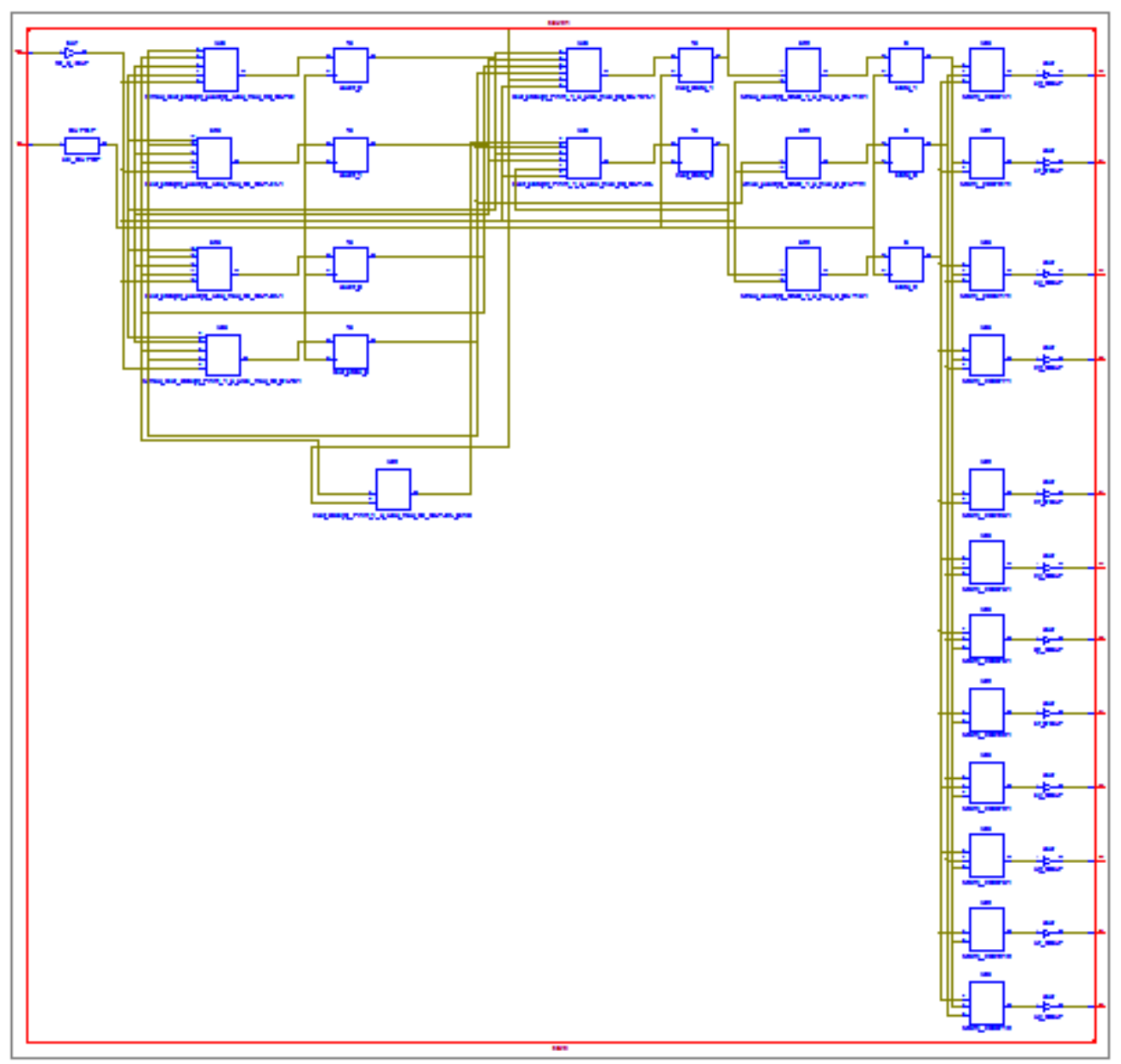

Figure 3 Internal Architecture of Technology Schematic view of Traffic Light Controller.

In the figure 3, Technology Schematic view of Traffic Light Controller are shown. This architecture shows different multiplexer, gates and other basic primitive circuits used in technology schematic.

\section{RELATED WORK}

Some researcher has work done on Simulation of voltage scaling aware mobile battery charge controller sensor on FPGA[1]. Some other researcher has work on Adaptive voltage scaling with in-situ detectors in commercial FPGAs[2]. Some other scientist has work on Energy Efficient Counter Design Using Voltage Scaling On FPGA[3]. Another researcher has worked on Leakage power reduction with various IO standards and dynamic voltage scaling in vedic multiplier on Virtex-6 FPGA[4]. Most of the researcher has worked on Design and implementation of a real-time traffic light control system based on FPGA[5]. Some author has Design of smart traffic light controller using embedded system[6]. Some of the other researcher has designed A 90nm low-power FPGA for battery-powered applications[7]. Some researcher has designed Low-power FPGA using pre-defined dual-Vdd/dual-Vt fabrics[8]. Another researcher has worked on Leakage power reduction with various IO standards and dynamic voltage scaling in vedic multiplier on Virtex-6 FPGA[9]. In our work we are using voltage scaling based design of energy efficient Traffic Light Controller on Virtex-7 FPGA family that consume low amount of power. 


\section{RESULT AND DISCUSSION}

Table 1 Power dissipation on different value of supply voltage Vccint at $25^{\circ} \mathrm{C}$.

\begin{tabular}{|l|l|}
\hline Voltage & Leakage power \\
\hline 1.2 & 0.229 \\
\hline 1.4 & 0.393 \\
\hline 1.6 & 0.706 \\
\hline 1.8 & 1.315 \\
\hline
\end{tabular}

There is a reduction of $46.31 \%, 70.11 \%$ and $82.58 \%$ in leakage power as the voltage is scale down from $1.8 \mathrm{~V}$ to $1.6 \mathrm{~V}, 1.4 \mathrm{~V}$ and $1.2 \mathrm{~V}$ respectively as shown in figure 4 and table 1.In which we have used output load capacitance value is $5 \mathrm{pF}$ and clock pulse period is 5ns.

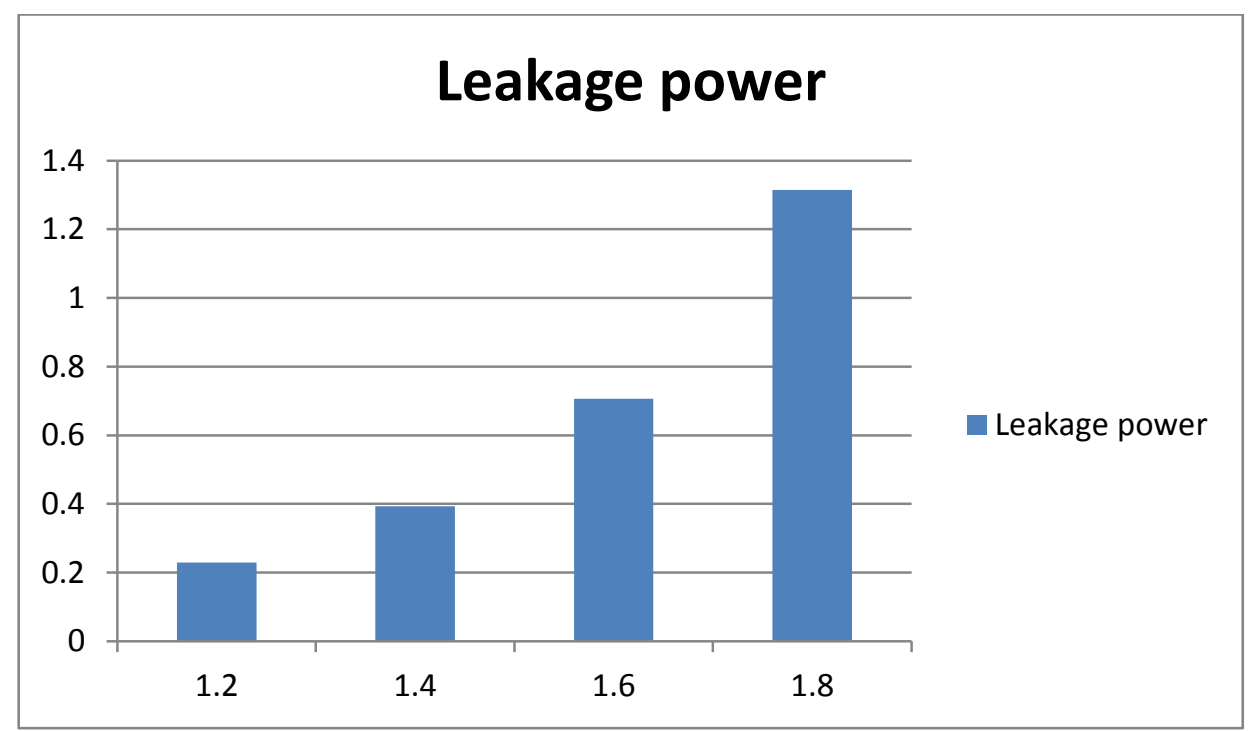

Figure 4 Graph of Leakage power on different level of voltage.

In this graph Leakage Power is rapidly increase with increase in supply voltage. There are increases in supply voltage from $1.2 \mathrm{~V}$ to $1.4 \mathrm{~V}, 1.6 \mathrm{~V}$ and $1.8 \mathrm{~V}$ as the increase in Leakage power are $0.229 \mathrm{~W}, 0.393 \mathrm{~W}, 0.706 \mathrm{~W}$ and $1.315 \mathrm{~W}$ respectively.

Table 2 Power dissipation on different value of supply voltage Vccint at $50^{\circ} \mathrm{C}$.

\begin{tabular}{|l|l|}
\hline Voltage & Leakage Power \\
\hline 1.2 & 0.585 \\
\hline 1.4 & 1.095 \\
\hline 1.6 & 2.132 \\
\hline 1.8 & 4.487 \\
\hline
\end{tabular}

There is a reduction of $52.48 \%, 75.59 \%$ and $86.96 \%$ in leakage power as the voltage is scale down from $1.8 \mathrm{~V}$ to $1.6 \mathrm{~V}, 1.4 \mathrm{~V}$ and $1.2 \mathrm{~V}$ respectively as shown in figure 5 and table 2.In which we have used output load capacitance value is $5 \mathrm{pF}$ and clock pulse period is $5 \mathrm{~ns}$. 
Gyancity Journal of Engineering and Technology, Vol.4, No.1, pp. 31-38, January 2018 ISSN: 2456-0065 DOI: 10.21058/gjet.2018.41004

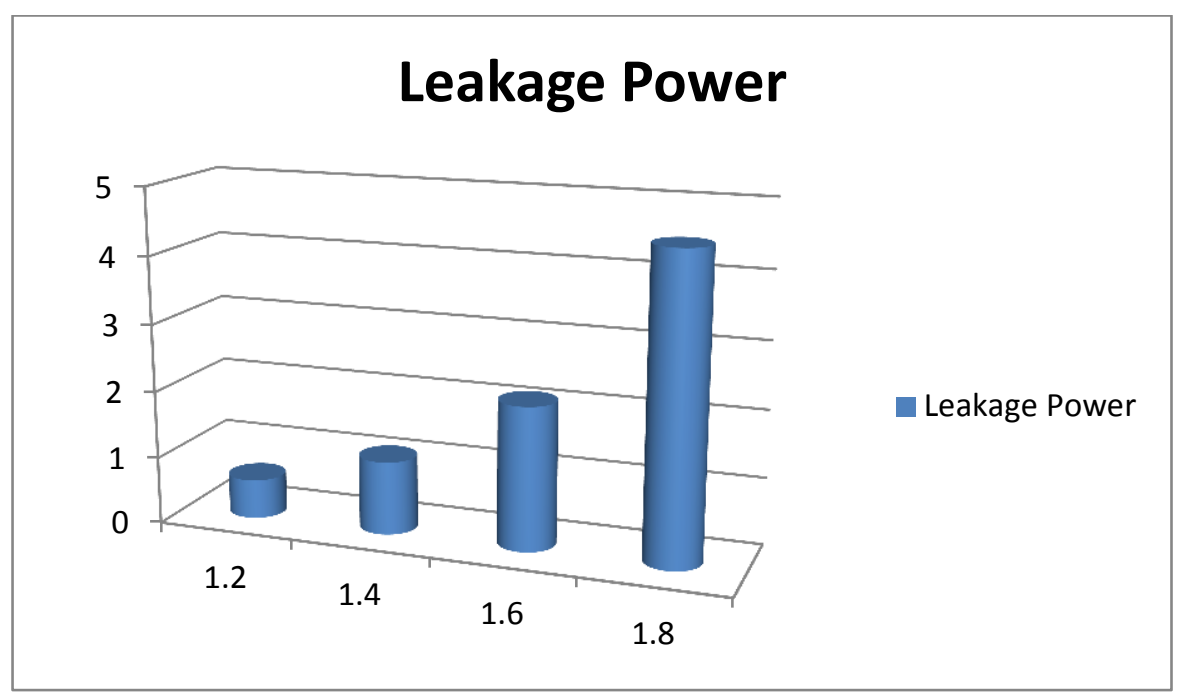

Figure 5 Graph of Leakage power on different level of voltage.

In this graph we have to see that leakage power is rapidly increase with increase in suooly voltage. There are increases in supply voltage from $1.2 \mathrm{~V}$ to $1.4 \mathrm{~V}, 1.6 \mathrm{~V}$ and $1.8 \mathrm{~V}$ as the increase in Leakage power are $0.585 \mathrm{~W}, 1.095 \mathrm{~W}, 2.132 \mathrm{~W}$ and $4.487 \mathrm{~W}$ respectively.

Table 3 Power Dissipation on different level of input voltage.

\begin{tabular}{|l|l|}
\hline Voltage & Clock power \\
\hline 1.2 & 0.003 \\
\hline 1.4 & 0.004 \\
\hline 1.6 & 0.005 \\
\hline 1.8 & 0.006 \\
\hline
\end{tabular}

There is a reduction of $46.31 \%, 70.11 \%$ and $82.58 \%$ in clock power as the voltage is scale down from $1.8 \mathrm{~V}$ to $1.6 \mathrm{~V}, 1.4 \mathrm{~V}$ and $1.2 \mathrm{~V}$ respectively as shown in figure 6 and table 3.In which we have used output load capacitance value is $5 \mathrm{pF}$ and clock pulse period is 5 ns.

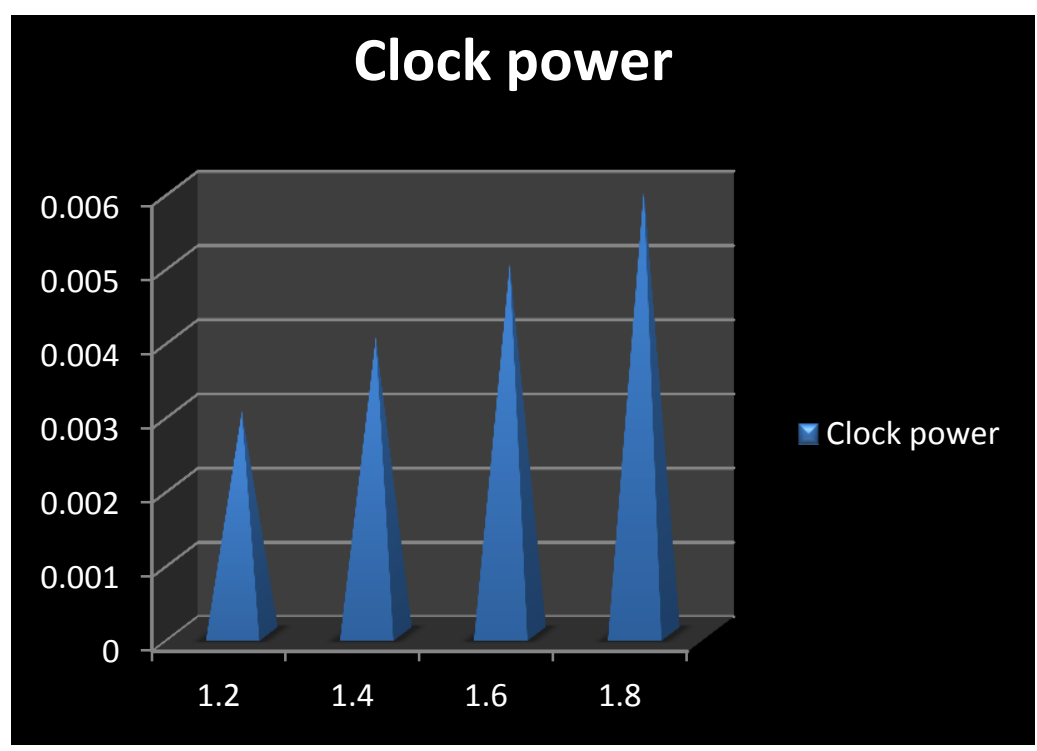

Figure 6 Graph of Clock Power on different level of voltage. 
Gyancity Journal of Engineering and Technology,

Vol.4, No.1, pp. 31-38, January 2018

ISSN: 2456-0065 DOI: 10.21058/gjet.2018.41004

\begin{tabular}{|c|c|c|c|c|}
\hline \multicolumn{5}{|c|}{ Device Utilization Summary } \\
\hline Slice Logic Utilization & Used & Available & Utilization & Note(s) \\
\hline Number of Slice Registers & 9 & 408,000 & $1 \%$ & \\
\hline Number used as Flip Flops & 9 & & & \\
\hline Number used as Latches & 0 & & & \\
\hline Number used as Latch-thrus & 0 & & & \\
\hline Number used as AND/OR logics & 0 & & & \\
\hline Number of Slice LUTs & 15 & 204,000 & $1 \%$ & \\
\hline Number used as logic & 15 & 204,000 & $1 \%$ & \\
\hline Number using O6 output only & 8 & & & \\
\hline Number using O5 output only & 0 & & & \\
\hline Number using O5 and O6 & 7 & & & \\
\hline Number used as ROM & 0 & & & \\
\hline Number used as Memory & 0 & 70,200 & $0 \%$ & \\
\hline Number used exclusively as route-thrus & 0 & & & \\
\hline Number of occupied Slices & 9 & 51,000 & $1 \%$ & \\
\hline Number of LUT Flip Flop pairs used & 15 & & & \\
\hline Number with an unused Flip Flop & 7 & 15 & $46 \%$ & \\
\hline Number with an unused LUT & 0 & 15 & $0 \%$ & \\
\hline Number of fully used LUT-FF pairs & 8 & 15 & $53 \%$ & \\
\hline Number of unique control sets & 1 & & & \\
\hline $\begin{array}{l}\text { Number of slice register sites lost } \\
\text { to control set restrictions }\end{array}$ & 7 & 408,000 & $1 \%$ & \\
\hline Number of bonded IOBs & 14 & 600 & $2 \%$ & \\
\hline Number of RAMB36E1/FIFO36E1s & 0 & 750 & $0 \%$ & \\
\hline Number of RAMB18E1/FIFO18E1s & 0 & 1,500 & $0 \%$ & \\
\hline Number of BUFG/BUFGCTRLs & 1 & 32 & $3 \%$ & \\
\hline Number used as BUFGs & 1 & & & \\
\hline Number used as BUFGCTRLs & 0 & & & \\
\hline $\begin{array}{l}\text { Number of } \\
\text { IDELAYE2/IDELAYE2_FINEDELAYs }\end{array}$ & 0 & 700 & $0 \%$ & \\
\hline $\begin{array}{l}\text { Number of } \\
\text { ILOGICE2/ILOGICE3/ISERDESE2s }\end{array}$ & 0 & 700 & $0 \%$ & \\
\hline
\end{tabular}


Gyancity Journal of Engineering and Technology,

Vol.4, No.1, pp. 31-38, January 2018

ISSN: 2456-0065 DOI: 10.21058/gjet.2018.41004

\begin{tabular}{|c|c|c|c|}
\hline $\begin{array}{l}\text { Number of } \\
\text { ODELAYE2/ODELAYE2_FINEDELAYs }\end{array}$ & 0 & 650 & $0 \%$ \\
\hline $\begin{array}{l}\text { Number of } \\
\text { OLOGICE2/OLOGICE3/OSERDESE2s }\end{array}$ & 0 & 700 & $0 \%$ \\
\hline $\begin{array}{l}\text { Number of } \\
\text { PHASER_IN/PHASER_IN_PHYs }\end{array}$ & 0 & 56 & $0 \%$ \\
\hline $\begin{array}{l}\text { Number of } \\
\text { PHASER_OUT/PHASER_OUT_PHYs }\end{array}$ & 0 & 56 & $0 \%$ \\
\hline Number of BSCANs & 0 & 4 & $0 \%$ \\
\hline Number of BUFHCEs & 0 & 168 & $0 \%$ \\
\hline Number of BUFRs & 0 & 56 & $0 \%$ \\
\hline Number of CAPTUREs & 0 & 1 & $0 \%$ \\
\hline Number of DNA_PORTs & 0 & 1 & $0 \%$ \\
\hline Number of DSP48E1s & 0 & 1,120 & $0 \%$ \\
\hline Number of EFUSE_USRs & 0 & 1 & $0 \%$ \\
\hline Number of FRAME_ECCs & 0 & 1 & $0 \%$ \\
\hline Number of GTHE2_CHANNELs & 0 & 28 & $0 \%$ \\
\hline Number of GTHE2_COMMONs & 0 & 7 & $0 \%$ \\
\hline Number of ICAPs & 0 & 2 & $0 \%$ \\
\hline Number of IDELAYCTRLs & 0 & 14 & $0 \%$ \\
\hline Number of IN_FIFOs & 0 & 56 & $0 \%$ \\
\hline Number of MMCME2_ADVs & 0 & 14 & $0 \%$ \\
\hline Number of OUT_FIFOs & 0 & 56 & $0 \%$ \\
\hline Number of PCIE_3_0s & 0 & 2 & $0 \%$ \\
\hline Number of PHASER_REFs & 0 & 14 & $0 \%$ \\
\hline Number of PHY_CONTROLs & 0 & 14 & $0 \%$ \\
\hline Number of PLLE2_ADVs & 0 & 14 & $0 \%$ \\
\hline Number of STARTUPs & 0 & 1 & $0 \%$ \\
\hline Number of XADCs & 0 & 1 & $0 \%$ \\
\hline Average Fanout of Non-Clock Nets & 2.83 & & \\
\hline
\end{tabular}

Table 4 Estimated value of slice logic device utilization summary. 


\section{Gyancity Journal of Engineering and Technology, Vol.4, No.1, pp. 31-38, January 2018 ISSN: 2456-0065 DOI: 10.21058/gjet.2018.41004}

\section{CONCLUSION}

Work is done in order to have an energy efficient traffic light controller design. This will help in designing low power traffic light controller for efficient output.Virtex-7 gives low power readings and so is efficient for designing of not only for traffic light controller but various electronic designs. It is obvious from these tables that at higher value of ambient temperature more power is consumed and vice versa. Through this investigation we are able to design a low power Traffic Light Controller with an efficient output.

\section{FUTURE SCOPE}

In future, we shall use ultra-scale FPGA for implementation of traffic light controller. These results can be used in future for making efficient Traffic Light Controller on FPGA. It is important to make this useful device efficient and a lot of work can be extended in this field further. We can also use different FPGA families like automotive Artix-7, automotive coolrunner-2, automotive Spartan, automotive Spartan-3A DSP, automotive Spartan-3A, automotive Spartan-3E, automotive Spartan-6, Spartan-3, Spartan-3E.

\section{REFERENCES}

[1]. Islam, S. M., Pandey, B., Siddiquee, S. M., \& Jaiswal, S. (2014). Simulation of voltage scaling aware mobile battery charge controller sensor on FPGA. In Advanced Materials Research (Vol. 893, pp. 798802). Trans Tech Publications.

[2].Nunez-Yanez, J. L. (2015). Adaptive voltage scaling with in-situ detectors in commercial FPGAs. IEEE Transactions on Computers, 64(1), 45-53.

[3]. Gupta, T., Verma, G., Kaur, A., Pandey, B., Singh, A., \& Kaur, T. (2015, April). Energy Efficient Counter Design Using Voltage Scaling On FPGA. In Communication Systems and Network Technologies (CSNT), 2015 Fifth International Conference on (pp. 816-819). IEEE.

[4]. Pandey, B., Rahman, M. A., Saxena, A., \& Das, B. (2016). Leakage power reduction with various IO standards and dynamic voltage scaling in vedic multiplier on Virtex-6 FPGA. Indian Journal of Science and Technology, 9(25).

[5]. Dong, H., Xiong, X., \& Zhang, X. (2014, April). Design and implementation of a real-time traffic light control system based on FPGA. In Proceedings of the 1st Conference on ASEE, April (pp. 3-5).

[6]. Thakare, V. S., Jadhav, S. R., Sayyed, S. G., \& Pawar, P. V. (2013). Design of smart traffic light controller using embedded system. ISOR-JE, 10(1), 30-3.

[7]. Tuan, T., Kao, S., Rahman, A., Das, S., \& Trimberger, S. (2006, February). A 90nm low-power FPGA for battery-powered applications. In Proceedings of the 2006 ACM/SIGDA 14th international symposium on Field programmable gate arrays (pp. 3-11). ACM.

[8]. Li, F., Lin, Y., He, L., \& Cong, J. (2004, February). Low-power FPGA using pre-defined dualVdd/dual-Vt fabrics. In Proceedings of the 2004 ACM/SIGDA 12th international symposium on Field programmable gate arrays (pp. 42-50). ACM.

[9]. Pandey, B., Rahman, M. A., Saxena, A., \& Das, B. (2016). Leakage power reduction with various IO standards and dynamic voltage scaling in vedic multiplier on Virtex-6 FPGA. Indian Journal of Science and Technology, 9(25). 